\title{
Students' Performance in Core and Service Courses: A Test of Valence-instrumentality Expectancy Theory
}

\author{
Bamikole O. Fagbohungbe ${ }^{1}$ \\ ${ }^{1}$ Department of Psychology, Faculty of Social Sciences, University of Lagos, Lagos, Nigeria \\ Correspondence: Bamikole O. Fagbohungbe, Department of Psychology, Faculty of Social Sciences, University \\ of Lagos, Lagos, Nigeria. E-mail: kolefagbo@yahoo.com
}

Received: April 2, 2012 Accepted: May 18, 2012 Online Published: July 5, 2012

doi:10.5539/jms.v2n2p236 URL: http://dx.doi.org/10.5539/jms.v2n2p236

\begin{abstract}
Spurred by the observed attitudes of students' to service courses and the attendant consequences of their inability to appreciate the relevance of courses offered by other departments, this study examined the effect of students positive or negative attitudes toward service or borrowed courses on student's performance in such courses. A non-experimental survey research design was used to study 200 students randomly selected from two departments (Accountancy and Insurance) from Lagos state Polytechnic. Anchored on the submission of valence-instrumentality- expectancy theory of Vroom (1964), it was hypothesed that students who score high in the service course appreciation questionnaire (SCAQ) would also score high in service courses. The result of independent t-test showed that the high and low groups were significantly different in their performance across the two dimensions (positive and negative) measured. The generalization from the study is that for students to acquire qualitative and functional education, intensive attention must be paid to all courses of study.
\end{abstract}

Keywords: service courses, valence, instrumentality, expectancy

\section{Introduction}

Over the years, problems in the educational sector have occupied a centre stage in the affair of the education policy makers in Nigeria. This is so, probably, because the bulk of human activities revolve around learning in the general frame of education. Ariwode (1998) submitted that the number and quality of students turned out by a particular country is a determinant factor of its development. Whereas, earlier, Lasa (1995) had raised alarm that 33.5 million Nigerians were stark illiterates. This calls for concern as this statistic fails to reinforce the quest for education for all by year 2,000.

Another aspect of the problem is the standard of education which bothers on student's performance. The recent outcry on the decline in the standard of education is disturbing enough. Akpeh (1998) disclosed that out of the total 459,870 candidates who took WAEC examination in November 1997,57,819 had their results cancelled due to examination malpractice. Poor funding, poor remuneration, shaky background, lack of concentration and other demotivating factors have been severally blamed for these woes. Of the various factors enumerated above, the one that concerns this author is inadequate concentration given by students to their studies, which in turn affects their performance. When mention is made of students' performance, logically reference is being made to the quality of their output in terms of scores across all courses or subjects studied.

If the nation is to positively develop, then it cannot afford the luxury of producing graduates who brandish certificates they cannot defend in terms of skills and knowledge (Dibella, 2007; Clegg \& Walsh, 2004). In order to produce complete and effective graduates through qualitative and functional education, curricula are designed to embraced two categories of courses. These are courses that are directly related to students' area of specialization, for example, different accountancy courses that covers almost all areas of accountancy and insurance courses for students who are specialist in insurance. The second categories are service courses that are only indirectly related to core courses or area of specialization. Such courses may be controlled by other departments, e.g., Psychology, Economics, English and Law from the general studies department. Sometime, they may be taught by employed experts within the specialty departments.

It has been observed that some students usually do not pay the required attention to service courses and this consequently adversely affects their performance. The pertinent question is, if these service courses are designed 
to make students acquire qualitative and functional education, complete, why is it that most of the time, they display negative attitude toward such courses? According to Bruch et al (2005) in their work "strategic change decisions": doing the right change right", advocated the need for consistency and diligence as factors that lead to positive change and performance.

The explanation for this behaviour could be sought in valence-instrumentality-expectancy (VIE) theory propounded by Vroom (1994). He postulates that people tend to expend more efforts toward reaching goals when both the probability of receiving a reward and the magnitude of the reward are known in advance. Thus, in a given situation, human behaviour is a joint function of subjective probability that the outcome will be forthcoming through personal efforts. Individuals will therefore choose the behaviour that they perceive as leading to the things they want.

Relating the theory to students performance in service courses, it could be reasonably argued that, it is because students could not perceive service courses as being part of the core courses that will make them become specialists, which no doubt is their ultimate goal, that is why they perform so poorly in such courses. Georgepoules, Mahancy and Jones (1957) state that people are motivated to do things which they feel have a high probability of leading to rewards which they value.

In view of the above, it is therefore hypothesized in the present research that students, who show higher appreciation of service courses, as they relate to core courses, would perform significantly higher in service courses than students with lower appreciation.

\section{Method}

\subsection{Participants}

200 students (107 males and 93 females) were used for the study. They were from two departments (Accountancy and Insurance) of the school of management and business studies of the Lagos State Polytechnic, Lagos Nigeria. In order to enhance the representativeness, students in each of the departments were drawn using stratified sampling method (i.e., 4 strata such as ND I, ND II, HND I and HND II respectively) thereby reducing sample bias. Thereafter, participants from each stratum were randomly selected. The participants' age ranged from 18 to 27 years with a mean age of 22.5.

\subsection{Instrument}

The instrument titled "service course appreciation questionnaire" (SCAQ) was used. It is an 8-item instrument constructed in the form of Likert Type summated rating Scale. This was used to measure subjects' appreciation of service courses. Specifically, the items required subjects to strongly agree, agree, undecided, disagree and greatly disagree. The instrument was able to categorise students into positive or negative in their attitude toward service courses. High score indicated positive attitude while low score indicated negative attitude. Thus, the instrument was able to classify the participants into two independent groups.

\subsubsection{Reliability and Validity of Instrument}

50 students were intensely interviewed on core and service courses. From their responses plus those that were extracted from literature emerged a 12 -item instrument. In order to ensure its content validity, the instrument was presented to 5 experts who are psychologists. 4-items were discarded for duplication and redundancy. At the end emerged an 8 -item scale. There was $93.5 \%$ agreement between the 5 raters.

In order to ensure the reliability of the, odd-even split-half reliability method produced $r=0.78$. Pearson product moment correlation analysis yielded $\mathrm{r}=0.78$. For the entire scale, Spearman-Brown prophecy formula yielded high degree of consistency $r=0.86, p>.001$. Thus the service course appreciation questionnaire (SCAQ) was both reliable and valid.

\subsection{Design}

The design for the study was a non-experimental survey research type that employed t-test for two independent samples. On the basis of the scores obtained in SCAQ, participants were categorised into high score group indicating positive attitude toward service courses and low score group indicating negative attitude toward service courses.

\subsection{Procedure}

There were 8 strata, 4 in each of the two departments (Accounting and insurance). 25 participants were then randomly selected from within each stratum given a total of 200 subjects (107 males and 93 females). Each of the participants completed the Service Course Appreciation Questionnaire (SCAQ). The entire questionnaires 
were subsequently scored. A score of 27.3 which is one standard deviation above mean 20 indicated high appreciation, while a score of 13.7 , one standard deviation below mean 20, indicated low appreciation. On the basis of the scores, therefore, subjects were classified into two district groups, the high score group (87 participants) and the low score group (113 participants).

Resulting to secondary source of data, the scores in Psychology (a compulsory service courses) for all participants in each of the two groups were extracted from records of previous performance. The marks obtained for the two groups were then compared for significant difference.

\section{Results}

Independent t-test was used to test the first hypothesis that students who show high appreciation of service courses would score higher (positive attitude) than students who scored lower (negative attitude). The result shows there was a statistically significant difference between high and low appreciation groups (positive and negative) df 199, $\mathrm{t}=5.35, \mathrm{p}<0.001$ (see Table 1).

Table 1. Independent t-test table showing the mean difference between high and low score on attitude toward service courses among students

\begin{tabular}{lllllll}
\hline Variable & S & N & X & Df & Tcal. & Pv \\
\hline Appreciation of service & Group 1 (high) & 86 & 47.80 & & & \\
courses & Group 2 (low) & 113 & 30.5 & 199 & $* 5.35$ & $\mathrm{P}<.05$ \\
\hline
\end{tabular}

Result is significant at $\mathrm{p}<.05$

The high positive attitude group recorded a higher mean of 47.80 as against 30.5 recorded by low or negative attitude group. This result supports hypothesis 1, which states that spurred by valence-instrumentality-expectancy theory, students who have high valence and high expectancy for service courses would perform high in such course, was supported.

Table 2. Independent t-test table showing the mean difference between scores of males and females in service courses appreciation questionnaire (SCAQ)

\begin{tabular}{lllllll}
\hline Variable & $\mathrm{N}$ & $\mathrm{X}$ & $\mathrm{SD}$ & $\mathrm{Df}$ & Tcal. & $\mathrm{Pv}$ \\
\hline Male & 61 & 45.93 & 4.94 & 118 & 1.23 & $\mathrm{P}>.05$ \\
Female & 54 & 45.04 & 4.5 & & & \\
\hline
\end{tabular}

Result is not significant at $\mathrm{p}>.05$

The second hypothesis, which stated that male participants would score higher than female participants' in the service courses appreciation questionnaire (SCAQ) is rejected. The result of independent t-test analysis did not show any significant difference $(t=1.23, \mathrm{df}=118, \mathrm{p}>.05)$ between male and female participants.

\section{Discussion}

Longe (2003) in his work "Industrial Psychology" in the hospitality business, noted the ambivalent attitude of students toward borrowed or service courses. According to longe (2003), students tend to see service courses as interference to make irrelevant course relevant. This perception has been confirmed in this study. The performance of participants who showed high appreciation, interpreted as high valence multiplied by high expectancy

Suggested by Vrooms theory performed significantly higher than participants who showed low valence and low expectancy. This finding also has supports in the submission of (Walton, 1985; Greenhalgh et al, 2005; Buchanan, et al, 2007; Culbertson, 2009).

Item analysis of participants' responses showed that among the low appreciation group, $97 \%$ indicated that service courses have no relevance to their core courses or their area of specialization. They felt that their education is qualitative and functional enough without those distracting service courses. It was not surprising therefore that they performed poorly in service course.

These findings prove that many students pay less attention to service courses than they pay to their core courses. It is only logical therefore to expect that with such attitude, they can only treat service courses with contempt, 
levity and perhaps with dislike. Cases abousesd their core courses in Lagos State Polytechnic (the setting for this study) of students who have passed their core courses, but are held back by service courses like English, Law, Economics, Psychology and Mathematics (Husted \& Michaiova, 2002; Buchanan et al, 2007).

With regard to the above revelation, students need to be helped. If $97 \%$ of low appreciation group in this study indicated that service courses have no role in acquiring qualitative and functional education, it is an indication of grave educational problem for the country, Nigeria. Therefore, they need to be helped to overcome their ignorance. In this regard, schools, departments and counseling centers should embark on orientation and enlightenment programmes, most especially for fresh students. Such programme will no doubt make students appreciate importance of acquiring complete education that takes one beyond immediate specialization (Leseure et al, 2004; Parry etal, 2001).

The second hypothesis which stated that the male participants would score higher than female participants on the service course appreciation questionnaire (SCAQ) was not supported. This could be because modernization has removed the female from the traditional cocoon of restriction. Today, they are ready to do what men can do, even much better.

Finally, on the theoretical aspect, the results proved the practical application of the instrumentality-expectancy theory by Vroom (1964) in real life situation. At the perceptual level, it could be argued that the students perform poorly in service course because they could not link such course with their defined goal of acquiring qualitative and functional education in line with the government educational policy. This was responsible for the display of low valence and low expectancy that lead to low scores among the participants.

\section{References}

Akpeh, I. (1988). The Week, April 20th, 22.

Ariwodo, C. O. (1998). The Punch, October 15th, 28.

Bruch, H., Gerber, P., \& Maier, V. (2005). Strategic change decisions: Doing the right change right. Journal of Change Management, 5(1), 97-107. http://dx.doi.org/10.1080/14697010500067390

Buchanan, D. A., Fitzgerald, L., \& Ketley, D. (2007). Sustainning change and aoiding containment: practice and policy. In D.A. Buchanan, Fitzgerald, L., \& Ketley, D. (Eds.), The sustainability and spread of organizational change. London: Routledge.

Clegg, C., \& Walsh, S. (2004). Change management: time for change. European Journal of Work and Organisational Psychology, 13(2), 217-239. http://dx.doi.org/10.1080/13594320444000074

Culbertson, S. S. (2009). Do satisfied employees mean satisfied customers? Academy of Management perspective, 23(1), 76-81. http://dx.doi.org/10.5465/AMP.2009.37008005

Debella, A. J. (2007). Critical perceptive of organizational change. Journal of change Management, 7(3), 231-242. http://dx.doi.org/10.1080/14697010701649707

Fagbohungbe, O. B., \& Longe, O. O. (1994). Industrial Psyhcology: X-ray of Behaviour in Nigerian Organisations. Lagos: KOTLEEB Consults.

Georgepoules, R. D., Mahoney, J. D., \& Jones, J. W. (1957). A Path-goal Approach to Productivity. Journal of Applied Psychology, 41, 345-353. http://dx.doi.org/10.1037/h0048473

Graeen, G. (1969). Instrumentality Theory of Work Motivation: Some Experimental Results and Suggested Modifications. Journal of Applied Psychology, 53, 21-25. http://dx.doi.org/10.1037/h0027100

Greenhalgh, T., Robert, G., \& Bate, P. (2005). Difusion of innovation in organizations: A systematic literature review. Oxford: BlackwellBTM books.

Husted, K., \& michaiova, S. (2002). Diagnosing and fighting knowledge-sharing hostility. Organisational Dynamics, 13(1), 60-73. http://dx.doi.org/10.1016/S0090-2616(02)00072-4

Lassa, P. N. (1995). Sunday Tribune, 19th November.

Lawler, E. E., \& Porteer, L. W. (1963). Perception Regarding Management Compensation. Industrial Relation, 3, 41-49. http://dx.doi.org/10.1111/j.1468-232X.1963.tb00808.x

Leseure, M. L., Baurer, J., \& Birdi, K. (2004). Adoption of promising practices: a systematic review of the

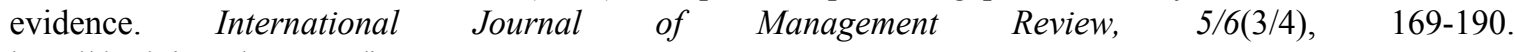
http://dx.doi.org/10.1111/j.1460-8545.2004.00102.x 
Longe, O. O. (2003). Industrial psychology in the hospitality business. Journal of School of Management and Business Studies, 2(2), 27-41.

Parry, C. S., \& Darling, M. J. (2001). Emergent learning in action: The after action review. The systems thinker, $12(8), 1-5$.

Vroom, H. (1964). Work and Motivation. New York: John Wiley.

Walton, R. E. (1985). From control to commitment in the workplace. Harvard Business Review, 63, 77-84. 